\title{
Barriers to preventive therapy for breast and other major cancers and strategies to improve uptake
}

\author{
Andrea DeCensi ${ }^{1,2}$, Mangesh A Thorat ${ }^{2,3}$, Bernardo Bonanni ${ }^{4}$, Samuel G Smith ${ }^{2,5}$ and Jack Cuzick ${ }^{2}$ \\ 1'Division of Medical Oncology, E.O. Ospedali Galliera, Mura delle Cappuccine 14, Genoa 16128, Italy \\ ${ }^{2}$ Centre for Cancer Prevention, Wolfson Institute of Preventive Medicine, Queen Mary University of London, London EC1M 6BQ, UK \\ ${ }^{3}$ Breast Services, Division of Surgery and Interventional Science, Whittington Hospital, Magdala Avenue, London N19 5NF, UK \\ ${ }^{4}$ Division of Cancer Prevention and Genetics, European Institute of Oncology, Via Ripamonti 435, Milan 20141, Italy \\ ${ }^{5}$ Health Behaviour Research Centre, University College London, London WC1E 7HB, UK
}

Correspondence to: Andrea DeCensi. Email: andrea.decensi@galliera.it

\begin{abstract}
The global cancer burden continues to rise and the war on cancer can only be won if improvements in treatment go hand in hand with therapeutic cancer prevention. Despite the availability of several efficacious agents, utilisation of preventive therapy has been poor due to various barriers, such as the lack of physician and patient awareness, fear of side effects, and licensing and indemnity issues. In this review, we discuss these barriers in detail and propose strategies to overcome them. These strategies include improving physician awareness and countering prejudices by highlighting the important differences between preventive therapy and cancer treatment. The importance of the agent-biomarker-cohort $(A B C)$ paradigm to improve effectiveness of preventive therapy cannot be overemphasised. Future research to improve therapeutic cancer prevention needs to include improvements in the prediction of benefits and harms, and improvements in the safety profile of existing agents by experimentation with dose. We also highlight the role of drug repurposing for providing new agents as well as to address the current imbalance between therapeutic and preventive research. In order to move the field of therapeutic cancer prevention forwards, engagement with policymakers to correct research imbalance as well as to remove practical obstacles to implementation is also urgently needed.
\end{abstract}

Keywords: aspirin, biomarkers, breast cancer, cancer, drug repurposing, preventive therapy, SERMs

Published: 24/11/2015

Received: 30/09/2015

ecancer 2015, 9:595 DOI: 10.3332/ecancer.2015.595

Copyright: () the authors; licensee ecancermedicalscience. This is an Open Access article distributed under the terms of the Creative Commons Attribution License (http://creativecommons.org/licenses/by/3.0), which permits unrestricted use, distribution, and reproduction in any medium, provided the original work is properly cited. 


\section{Introduction}

Significant improvements in cancer treatments have occurred over the past few decades, but our cancer prevention efforts have not kept pace with them. As a result, the global cancer burden continues to rise. Therapeutic cancer prevention is an effective and essential tool in our fight against cancer, and yet utilisation of preventive therapy has been woefully inadequate. Use of drugs to cut risk by $40-50 \%$ in the top $20 \%$ of the general population can achieve a $30 \%$ reduction in the cancer burden (Figure 1). However, unlike early detection/screening interventions, at an individual level, the success of therapeutic prevention goes unnoticed, while the side effects get noticed, leading to a failure to appreciate its value within the medical profession. To elucidate this point further, an overdiagnosed case that would not become symptomatic within the person's lifetime is actually a failure of a screening intervention, yet it often gets considered as a success by the public because from this individual's point of view, his/her life was saved by cancer being caught early. For preventive therapy, we cannot identify individuals whose cancer was prevented or risk was substantially reduced because of the lack of measurable biomarkers of efficacy, which currently exist for other diseases, including cardiovascular diseases, prevention of diabetes complications or osteoporotic bone fractures. Therefore, from that person's point of view, they either took medication unnecessarily or in the worst case scenario, unnecessarily suffered the adverse effects of such therapy. Thus, preventive therapy for cancer is often discounted as overtreatment and used as an example of overmedicalisation. Understanding and overcoming such perception differences, along with other barriers, is essential if we are to realise the full potential of this approach for cancer control. In this short review, we discuss important barriers to therapeutic cancer prevention, strategies to overcome these barriers and future research needs (Table 1), using breast cancer prevention as the main example.

\section{Breast cancer prevention}

Breast cancer incidence continues to increase with an estimated 1.6 million cases occurring worldwide each year and it is now the commonest cancer in women, making it an ideal cancer for prevention. Strong evidence now exists from nine large phase-III trials that preventive therapy with selective oestrogen receptor modulators (SERMs) reduces breast cancer incidence by 40\% [1]. More recently, aromatase inhibitors (Als) have also shown a more than $50 \%$ reduction in breast cancer in two phase-III trials in postmenopausal women [2, 3].

In 1998, the US FDA approved tamoxifen for primary breast chemoprevention in both premenopausal and postmenopausal women at high risk based on the Gail model. In 2007, the food and drug administration (FDA) also approved raloxifene for primary breast cancer chemoprevention for postmenopausal women using the same risk model. Current ASCO guidelines suggest including tamoxifen in discussion of risk reduction strategies for high-risk women [4-6]. The UK National Institute for Health and Care Excellence (NICE) guidelines also recommend tamoxifen or raloxifene as preventive therapy in women with lifetime breast cancer risk above 30\% [7].

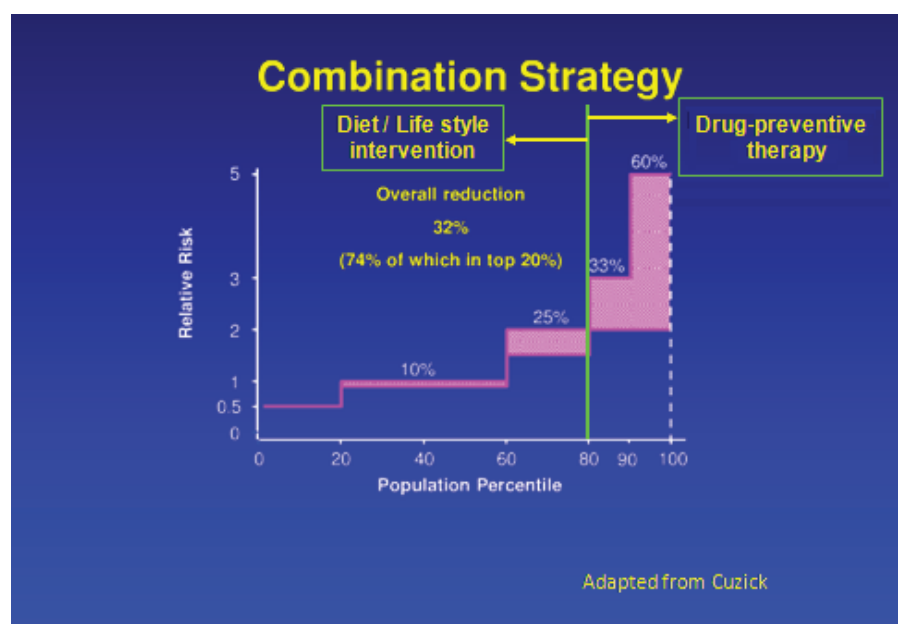

Figure 1. Combination strategy to reduce breast cancer burden worldwide. 
Table 1. Barriers to preventive therapy and strategies to overcome these barriers.

\begin{tabular}{|l|l|}
\hline \multicolumn{1}{|c|}{ Barriers } & \multicolumn{1}{c|}{ Strategies to overcome barriers } \\
\hline Physicians' lack of knowledge/prejudices. & Increasing physician awareness and countering prejudices. \\
\hline Individual's lack of knowledge. & $\begin{array}{l}\text { Improving physician-patient communication and information sharing; } \\
\text { educational interventions. }\end{array}$ \\
\hline Individual's fear of side effects. & $\begin{array}{l}\text { Exploring re-purposing of commonly used agents with well-documented } \\
\text { safety profile. }\end{array}$ \\
\hline $\begin{array}{l}\text { Underestimation of benefits and/or } \\
\text { overestimation of harms. }\end{array}$ & $\begin{array}{l}\text { - Acknowledging different needs of risk prediction for different diseases } \\
\text { and agents. } \\
\text { Refining risk prediction and risk communication. } \\
\text { - Development of biomarkers that can be frequently monitored by } \\
\text { non-invasive means. }\end{array}$ \\
\hline Adverse effects of agents. & $\begin{array}{l}\text { Exploring strategies to reduce adverse effects, e.g., dosing } \\
\text { modifications. }\end{array}$ \\
\hline Lack of well-proven agents for several cancers. & Increased focus on preventive research, particularly in academia. \\
\hline Licensing and off-label use issues. & \begin{tabular}{l} 
Policy engagement. \\
\hline
\end{tabular}
\end{tabular}

\section{Low uptake of preventive therapy for breast cancer}

Tamoxifen uptake for eligible high-risk women remains very low primarily due to concerns about side effects and lack of demonstrated mortality reduction [6, 8]. Even for premenopausal women attending high-risk clinics where the risk benefit ratio of tamoxifen is largely favourable, the rate of tamoxifen uptake has been reported to be only 10\% [9] and is regarded as a preference-sensitive decision [8-10]. It is estimated that about $7 \%$ of 50 -year-old women would be eligible for preventive therapy based on the NICE criteria of a $>5 \% 10$-year risk, and this number would approach 15\% if SNP scores and mammographic density were also used [11-13]. The uptake of breast cancer preventive therapy has been below $1 \%$ in spite of a potential population of approximately 10 million high-risk women aged 35-79 years in the United States according to FDA criteria [14] and similar figures in Europe who may be eligible for breast cancer preventive therapy according to high-risk assessment models. In 2010, the vast majority of women reporting use of preventive therapy for breast cancer prevention in the USA were using raloxifene; 96,890 [95\% confidence interval (Cl), 41,277-192,391] of approximately 45 million women aged $50-79$ years were taking raloxifene as compared to 20,598 (95\% Cl: 518-114,864) of approximately 77 million women aged 35-79 years using tamoxifen [15]. The prevalence of preventive therapy was however very low for both drugs - 0.03\% (95\% Cl: 0.001-0.15) for tamoxifen and $0.21 \%(95 \% \mathrm{Cl}$ : 0.09-0.43) for raloxifene [15]. Data from the US National Health Interview Surveys show that breast cancer preventive therapy use was similar in years 2000 and 2005, and the overall pictures suggests a shift away from tamoxifen and towards raloxifene for this purpose [16].

\section{Reasons for the low uptake}

Low uptake of preventive therapy is a result of multitudes of factors [17]. An important factor is physicians' lack of knowledge about preventive therapy. Also important are their prejudices, lack of ability to make accurate risk predictions and communication challenges. It is important to distinguish between oncologists in breast clinics who regularly prescribe drugs such as tamoxifen and Als for the treatment of cancer and general practitioners (GPs) or family physicians who do not routinely prescribe these drugs. GPs are often the first point of contact for a woman to discuss her concern regarding breast cancer risk and prevention, and women often do not get a chance to discuss this with an oncologist or genetic risk counsellor. Nononcologist physicians may be reluctant to prescribe tamoxifen due to concerns about side effects or their own lack of sufficient information about risk reduction options [18-20]. In a study of physicians in California, Kaplan et al reported that frequent barriers to initiating cancer prevention counselling were 'not enough time' (40.3\%) and 'insufficiently informed about risk reduction options' (19.1\%) [18]. This is particularly important since a physician's recommendation is a key factor in a person's 
decision [20, 21]. Similarly, data from a clinical trial also suggest that a dedicated caregiver-participant relationship is a critical component for an elevated participation [22]. In an Italian study of over 265 subjects who entered a prevention trial of tamoxifen at low dose and 192 who declined to participate [22], the three most frequent reasons for entry were willingness to participate in a research programme $(60 \%)$, the need/desire to receive frequent medical care $(58 \%)$, and the desire to contribute to medical knowledge (44\%), whereas the top three reasons for refusal were fear of medication abuse (33\%), concern about adverse effects $(31 \%)$, and advice against enrolment by their family or specialist doctor (24\%) [22]. While family history is a common factor in a physician's consideration of cancer prevention for his/her patient, other risk factors like diagnosis of proliferative or atypical benign breast disease [23] are often overlooked - despite clear evidence of a significantly higher breast cancer risk in such women. These issues underscore the need to establish a personal relationship between the high-risk individual and a well-informed caregiver. However, efforts to increase awareness of preventive therapy among physicians [24-26], including calls for developing support tools [27] have been adversely impacted by scepticism of other opinion leaders [28, 29]. Unsurprisingly, in a recent survey conducted among over 200 breast cancer specialists during different breast cancer meetings in Italy and Switzerland or sent electronically among the alumni of the European School of Oncology, the top three important or very important reasons for low uptake were the following: (1) drugs may have serious side effects; (2) no evidence for a reduction in mortality; (3) drugs are off label in Europe (manuscript in preparation). The issue of lack of effect on mortality discussed in detail below is a main point of contention. This suggests that the differences between use of drugs for cancer treatment and cancer prevention, and the need of a different approach/ thinking for each are not always sufficiently appreciated by clinicians regularly treating cancer. Surmounting this obstacle may require a cultural change in the oncology community.

A high-risk individual's personal reluctance to undergo preventive therapy is determined by several factors. These include underestimation of benefits and/or overestimation of harms [20,30]. Our inability to accurately estimate risk in certain high-risk categories like benign breast diseases further aggravates this problem [16, 23] and research to improve our risk-prediction models urgently needed [23]. However, reluctance has been reported even in those situations where individuals clearly recognise [31] a net benefit with preventive therapy $[20,30]$ and provision of information [32] through educational interventions [8] does not improve uptake. The fear of side effects was the main reason for not electing to take preventive therapy in a study by Port et al [30]. Behavioural research indicates that a proportion of women perceive the risks of side effects as more probable and as more dangerous than the risks of breast cancer [33, 34] and this is reflected in their becoming highly averse to the suggestion that a preventive therapy may produce a side effect [35]. In this background, it is also important to note that some studies $[22,33,36]$ show a reasonable rate of women's acceptance of preventive therapy, and therefore, it is possible to improve uptake.

Other barriers to preventive therapy [37] include poor commercial interest in the use of approved study medications due to concerns about influencing their established use [38] and liability issues, especially for off label use [39] and these will need to be tackled through changes in policy provisions.

\section{Strategies to improve uptake}

Strategies to improve uptake of currently available preventive therapy start with increasing physician and patient awareness and countering prejudices. Refining risk prediction and patient communication would also be valuable. Research needs and strategies to move the cancer prevention field forward are discussed later in this paper.

\section{Countering prejudices - the issue of lack of reduction in mortality}

Preventive therapy trials of SERMs [1] have not yet shown a reduction in breast cancer-specific or all-cause mortality, and this has been one of the main arguments $[28,29]$ against their use. Those not in favour of adopting therapeutic cancer prevention $[28,29]$ often fail to appreciate two issues; the lack of power of SERM trials to show mortality benefit at current length of follow-up and the substantial impact of just reducing cancer incidence.

The majority of SERM trials have a long follow-up, yet it is still too early to evaluate its effect on breast cancer mortality since breast cancer incidence still exceeds mortality by more than 10-fold [40], and therefore, the number of events needed to see a mortality impact is still inadequate. Furthermore, although IBIS-I (503 invasive breast cancers but only 57 breast cancer deaths) reported a 16-year median follow-up [40], the median follow-up after cancer diagnosis is only 8 years, which is still inadequate to evaluate effect on mortality [41]. 
The oncology community often relies on endpoints such as quality of life and in-hospital stay to determine the best treatment options in the absence of a clear impact on survival or mortality. Breast cancer incidence is still increasing worldwide and preventive therapy can avoid this dreaded diagnosis in a large number of women. This not only has potential individual benefits like avoiding a negative impact on the quality of life and avoiding treatments with substantial morbidity, but will also have a positive impact on healthcare systems in terms of improved allocation of limited treatment resources and thereby improving outcomes at a lower cost.

A somewhat similar issue has affected prostate cancer prevention by the use of $5 \alpha$-reductase inhibitors (5-ARIs) as well [42]. A significant reduction in Gleason 6 or below cancers, and an increase in high-grade tumours was seen in prostate cancer prevention trial (PCPT) [43] and Reduction by Dutasteride of Prostate Cancer Events (REDUCE) trials [44], but not in observational studies [45]. A similar long-term survival in PCPT arms [46] and the evidence for potential cost-effectiveness [47] of prevention by the use of 5-ARIs favour this intervention to reduce the ever increasing burden of prostate cancer.

\section{Increasing physician and patient awareness}

Increasing physician and particularly patient awareness is essential. For example, media coverage that led to increased awareness of aspirin's cancer prevention role [48] resulted in a more than 10-fold increase in its sales in the short term [49]. While this may be largely due to aspirin being a commonly used drug available over the counter, awareness does seem to play a role.

\section{Policy matters}

Debates in medical journals often exclude the practical barriers to the implementation of preventive therapy. These need to be addressed at policy level, and therefore, engagement with policymakers is essential to eliminate such practical barriers. For example, poor commercial appeal of approved study medications [38] results in lack of licensing for preventive indications which in turn creates off-label use indemnity issues. Changes in policy could be brought about by new legislation and although yet unsuccessful, bills like the Off-patent Drugs Bill 2014-2015 presented in the UK parliament are a way forward [50].

\section{Research priorities to improve therapeutic cancer prevention}

\section{Improving risk prediction - lessons from cardiovascular prevention}

Unlike therapeutic cancer prevention, preventive therapy is very widely accepted and routinely used in the field of cardiovascular diseases. It is crucial to understand the lessons learned from cardiovascular medicine and also important to identify the differences so that alternative strategies or further research can be pursued for improving cancer prevention.

The key ingredients for the successful progress of cancer prevention are summarised in the ABC (agents-biomarkers, cohorts) paradigm [51] (Figure 2). However, the development of new agents in cancer prevention is hampered by the lack of suitable biomarkers and targets. Establishing breast cancer chemoprevention as standard clinical practice as has been done in cardiovascular medicine will require advances in many different fields, including biomarker research, the development of more powerful tools to identify at risk individuals (cohorts), methods to better communicate the risks and benefits of treatments, and establishing innovative trial designs.

Risk factors such as high low-density lipoprotein (LDL) cholesterol or high blood pressure have been elevated to the status of a disease in cardiovascular prevention and health authority endorsement for treating these has been obtained. This has been possible not only because these risk factors correlate well with cardiovascular disease but also because these are good surrogates of response and can be frequently monitored by non-invasive means. Barring notable exceptions of a few genetic tests like breast cancer (BRCA) mutation, which serve as strong risk factors but are applicable to a very small fraction of the general population, and surrogates like change in breast density for tamoxifen response [52], there is a great dearth of risk factors and surrogate markers of response in the field of therapeutic cancer prevention. 


\section{Key Ingredients in cancer preventive medicine: the $A B C$ paradigm}

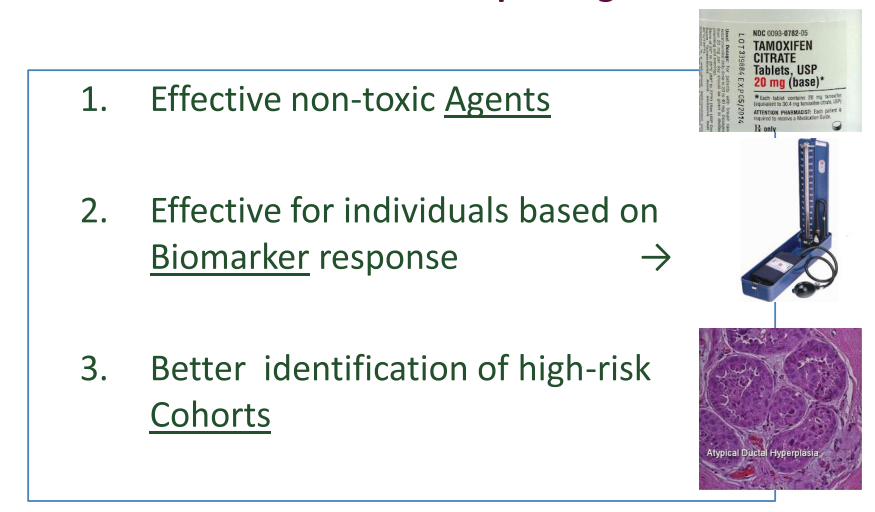

Figure 2. Key elements for cancer prevention: the ABC paradigm. (From De Censi A, Discussion abstract LBA504, ASCO June 5, 2011 [51].)

Two important types of risk factors play a role from the preventive therapy perspective: risk factors for the disease in question and factors for predicting the risk of side effects of a particular preventive therapy. The relative importance of these is influenced by the spectrum of cancers that could be prevented. For example, aspirin has preventive effects in a range of different cancers [48, 53], so that identification of high-risk individuals is not only difficult, but also not so necessary. On the other hand, aspirin's side effects are severe only in a small proportion of individuals [54] so that the ability to reliably identify such individuals and not offer aspirin to them becomes more important for improving the overall benefit-harm profile of the drug for cancer prevention. In contrast, the benefits of endocrine agents are expected only for breast cancer, and a key priority is to better identify women at high risk of developing this specific disease.

Refining existing biomarkers and development of new biomarkers of cancer risk, response to therapy, and the risk of side effects of agents is urgently needed. Recent developments in the field of cell-free DNA (cfDNA)/circulating tumour DNA (ctDNA) [55] may provide an opportunity identify/develop biomarkers of cancer risk and response to therapy that can be repeatedly monitored in a non-invasive manner. Assessment and validation of newer individualised and preference-sensitive interactive tools is also needed to improve patient communication [56].

\section{Revisiting existing agents and drug re-purposing}

Improving and individualising our estimation of benefit-harm balance alone will, however, not suffice as the findings from behavioural research repeatedly suggest that the perception of side effects is one of the main barriers. It is therefore also essential that drugs used for cancer prevention not only have high efficacy but also have a very safe side effect profile from an at-risk individual's perspective. New compounds may not be able to overcome this perception hurdle, but, repurposed drugs that are widely used for other purposes (e.g. aspirin, metformin) may be more acceptable as evidenced by the aspirin example above [49]. Similarly, dosing of existing agents could also be altered to improve the side effect profile without losing efficacy.

One simple strategy is to lower the dose of drugs that are in common use in the adjuvant setting based on the notion that prevention of cancer cells could occur at a lower dose than eradicating established tumour cells. This was done for antihypertensive agents in the polypill for stroke prevention in the general population [57]. A second approach is to adopt an intermittent administration similarly to that used in the chemotherapy setting in an attempt to minimise risks while retaining benefits. A meta-analysis of the adjuvant tamoxifen clinical trials reported that the benefits of tamoxifen in terms both of recurrence and mortality appeared to be equivalent between $20 \mathrm{mg} / \mathrm{day}$ and $30-40 \mathrm{mg} / \mathrm{day}$ [58]. In a randomised biomarker trial conducted in the late 1990s [59], a dose reduction to $10 \mathrm{mg}$ every other day did not affect the activity of tamoxifen on total cholesterol, insulin-like growth factor 1 (IGF-1) and C-reactive protein using an ultrasensitive assay. In a window of opportunity three-arm randomised trial, the antiproliferative effects of tamoxifen at $1 \mathrm{mg} /$ day and $5 \mathrm{mg} /$ day relative to those of the standard dose of $20 \mathrm{mg} /$ day were assessed on Ki-67 labelling index (LI) in breast tumour specimens using a pre-surgical model in 120 breast cancer patients [60]. Labelling of Ki-67 decreased in all three tamoxifen dose-level groups, with no difference in the magnitude of reduction among 
the groups $(p=0.81)$. In the hormone replacement therapy (HRT) opposed by low-dose tamoxifen (HOT study), a multicentre phase-III trial in 1884 postmenopausal healthy women, current or de novo HRT users were randomised to either tamoxifen $5 \mathrm{mg} / \mathrm{day}$ or placebo for 5 years, with 5 years of follow-up. A trend towards a beneficial effect from low-dose tamoxifen in reducing BC events was observed (risk ratio (RR): $0.80 ; 95 \% \mathrm{Cl}$ : 0.44-1.46) with greater efficacy being seen in luminal-A tumours (RR: $0.32 ; 95 \% \mathrm{Cl}: 0.12-0.86$ ), HRT users $<5$ years (RR: 0.35 ; 95\% Cl: 0.15-0.82) and women completing at least 12 months of treatment (RR: $0.49 ; 95 \%$ Cl: 0.23-1.02) [61]. The utility of low-dose tamoxifen as preventive therapy is also being evaluated in a different cohort of high-risk women such as women with oestrogen receptor-positive ductal carcinoma in situ (ER-positive DCIS) $[62,63]$ and Hodgkin's lymphoma survivors who were previously treated with $\geq 15$ Gy of mantle irradiation to the chest before age 30 [64].

Similarly, aspirin's preventive benefits on cancer have been seen for all daily doses above $75 \mathrm{mg}$ and, in the absence of greater efficacy at higher doses, low-dose aspirin appears to be a reasonable choice for cancer prevention in view of a lower risk of side effects [48, 54].

Along this line, additional agents may be repurposed as preventive medications after careful determination of the minimal effective dose. For example, exemestane, an irreversible aromatase inhibitor, has showed an overall $65 \%$ reduction in all breast cancers and a $73 \%$ reduction specifically for ER-positive breast cancer in the intervention arm compared to the placebo group [3]. However, the standard dose employed in the treatment setting was used also for prevention, and the benefit-harm ratio of adverse effects such as bone density loss, musculoskeletal pain, and climacteric syndrome associated with treatment may be less favourable in the prevention setting [65]. Since the oestradiol suppression persists for at least 5 days after administration of a single dose [66], it seems reasonable to consider reducing the dose or changing the administration schedule, while still maintaining a significant oestradiol reduction. A dose of $10 \mathrm{mg}$ daily of exemestane has been shown to be equivalent to $25 \mathrm{mg}$ for suppressing oestradiol levels [67]. A window of opportunity biomarker trial has been planned in which participants will be randomised to receive either exemestane $25 \mathrm{mg} /$ day or $25 \mathrm{mg} /$ three times a week or a single dose of $25 \mathrm{mg} / \mathrm{week}$ for $5( \pm 1)$ weeks. The primary endpoint will be the change in serum oestradiol using an ultrasensitive assay after $5( \pm 1)$ weeks treatment [68].

\section{Strategic shift to more preventive research}

The failure [69] of agents like beta carotene [70-73] and vitamin E [74-76] in large trials of lung cancer prevention underscores the need for identification of newer targets and agents, which can only be accomplished through increased preventive research. The pharmaceutical industry's investment in the development of cancer preventive agents is disproportionately low as compared to that in the development of agents for cancer treatment. Industry's focus on profits means that this imbalance is unlikely to be corrected in the foreseeable future and therefore academia and other non-pharmaceutical institutions, including government agencies need to take a more active role in the development of agents for cancer prevention. The development of a new drug requires substantial investment which is not readily available through academic research funding, whereas repurposing of a drug for new indication is likely to cost substantially less. Drug repurposing could provide a more achievable focus for developing therapeutic cancer prevention and is one in which academia can play a major role.

\section{Conclusions}

Cancer incidence continues to increase worldwide and our war on cancer cannot be won without effective cancer prevention measures that include lifestyle modifications as well as therapeutic prevention. Despite the availability of several efficacious cancer prevention agents, uptake of cancer preventive therapy remains woefully inadequate. Increasing the awareness of preventive therapy among physicians - along with highlighting the important differences between preventive therapy and cancer treatment so as to eliminate prejudices against preventive therapy is necessary. Improving cancer risk and drug response prediction to maximise the benefit-harm balance, coupled with repurposing and improving the safety profile of existing agents by experimenting with dose is urgently needed. The development of newer preventive agents will not be enough by itself and engagement with policymakers cannot be ignored in order to remove practical obstacles to implementation of existing effective agents.

\section{Conflicts of interest}

The authors declare that there are no conflicts of interest. 


\section{Funding}

This study was partially supported by Gruppo Bancario Credito Valtellinese, and Cancer Research UK programme award (C569/A16891).

Smith is supported by a Cancer Research UK Postdoctoral Fellowship (C42785/A17965).

\section{Disclaimer}

The findings and conclusions in this report are those of the authors and do not represent the official position of the authors' respective institutions.

\section{Acknowledgments}

This work was presented at the WP2 EurocanPlatform meeting: European recommendations for biomarker-based chemoprevention trials, October 13-14, 2014, at the European Institute of Oncology, Milan, Italy.

\section{References}

1. Cuzick J, Sestak I and Bonanni B et al (2013) Selective oestrogen receptor modulators in prevention of breast cancer: an updated meta-analysis of individual participant data Lancet 381(9880) 1827-1834 DOI: 10.1016/S0140-6736(13)60140-3 PMID: 23639488 PMCID: $\underline{3671272}$

2. Cuzick J, Sestak I and Forbes JF et al (2014) Anastrozole for prevention of breast cancer in high-risk postmenopausal women (IBIS-II): an international, double-blind, randomised placebo-controlled trial Lancet 383(9922) 1041-1048 DOI: 10.1016/S0140$\underline{6736(13) 62292-8}$

3. Goss PE, Ingle JN and Ales-Martinez JE et al (2011) Exemestane for breast-cancer prevention in postmenopausal women N Engl J Med 364(25) 2381-2391 DOI: 10.1056/NEJMoa1103507 PMID: 21639806

4. Visvanathan K, Chlebowski RT and Hurley P et al (2009) American society of clinical oncology clinical practice guideline update on the use of pharmacologic interventions including tamoxifen, raloxifene, and aromatase inhibition for breast cancer risk reduction J Clin Oncol 27(19) 3235-3258 DOI: 10.1200/JC0.2008.20.5179 PMID: 19470930 PMCID: 2716943

5. Chlebowski RT, Col N and Winer EP et al (2002) American society of clinical oncology technology assessment of pharmacologic interventions for breast cancer risk reduction including tamoxifen, raloxifene, and aromatase inhibition $J$ Clin Oncol 20(15) 3328-3343 DOI: 10.1200/JCO.2002.06.029 PMID: 12149307

6. Visvanathan K, Hurley $P$ and Bantug $E$ et al (2013) Use of pharmacologic interventions for breast cancer risk reduction: American society of clinical oncology clinical practice guideline J Clin Oncol 31(23) 2942-2962 DOI: 10.1200/JCO.2013.49.3122 PMID: 23835710

7. National institute for health and clinical excellence (2013) Familial breast cancer: classification and care of people at risk of familial breast cancer and management of breast cancer and related risks in people with a family history of breast cancer CG164: national institute for health and clinical excellence 2013 Report No.: CG164 Contract No.: CG164

8. Ropka ME, Keim J and Philbrick JT (2010) Patient decisions about breast cancer chemoprevention: a systematic review and meta-analysis J Clin Oncol 28(18) 3090-3095 DOI: 10.1200/JCO.2009.27.8077 PMID: 20458026 PMCID: 2903338

9. Donnelly LS, Evans DG and Wiseman J et al (2014) Uptake of tamoxifen in consecutive premenopausal women under surveillance in a high-risk breast cancer clinic Br J Cancer 110(7) 1681-1687 DOI: 10.1038/bjc.2014.109 PMID: 24594998 PMCID: $\underline{3974072}$ 
10. Melnikow J, Paterniti D and Azari R et al (2005) Preferences of women evaluating risks of tamoxifen (POWER) study of preferences for tamoxifen for breast cancer risk reduction Cancer 103(10) 1996-2005 DOI: 10.1002/cncr.20981 PMID: 15825209

11. Brentnall $A$, Evans $D$ and Cuzick $J$ (2013) Value of phenotypic and single-nucleotide polymorphism panel markers in predicting the risk of breast cancer J Genet Syndr Gene Ther 4(202) 2 DOI: 10.4172/2157-7412.1000202

12. Warwick J, Birke $\mathrm{H}$ and Stone $\mathrm{J}$ et al (2014) Mammographic breast density refines Tyrer-Cuzick estimates of breast cancer risk in high-risk women: findings from the placebo arm of the international breast cancer intervention study I Breast Cancer Res 16(5) 451 DOI: 10.1186/s13058-014-0451-5 PMID: 25292294 PMCID: $\underline{4303130}$

13. Brentnall AR, Evans DG and Cuzick J (2014) Distribution of breast cancer risk from SNPs and classical risk factors in women of routine screening age in the UK Br J Cancer 110(3) 827-828 DOI: 10.1038/bjc.2013.747 PMID: 24448363 PMCID: 3915120

14. Freedman AN, Graubard BI and Rao SR et al (2003) Estimates of the number of US women who could benefit from tamoxifen for breast cancer chemoprevention J Natl Cancer Inst 95(7) 526-532 DOI: 10.1093/jnci/95.7.526 PMID: 12671020

15. Waters EA, McNeel TS and Stevens WM et al (2012) Use of tamoxifen and raloxifene for breast cancer chemoprevention in 2010 Breast Cancer Res Treat 134(2) 875-880 DOI: 10.1007/s10549-012-2089-2 PMID: 22622807 PMCID: 3771085

16. Waters EA, Cronin KA and Graubard BI et al (2010) Prevalence of tamoxifen use for breast cancer chemoprevention among U.S. women Cancer Epidemiol Biomarkers Prev 19(2) 443-446 DOI: 10.1158/1055-9965.EPI-09-0930 PMID: 20142242 PMCID: $\underline{3038785}$

17. Smith SG, Sestak I and Forster A et al Factors affecting uptake and adherence to breast cancer chemoprevention: a systematic review and meta-analysis Submitted

18. Kaplan CP, Haas JS and Perez-Stable EJ et al (2005) Factors affecting breast cancer risk reduction practices among California physicians Prev Med 41(1) 7-15 DOI: 10.1016/j.ypmed.2004.09.041 PMID: 15916987

19. Malek K, Fink AK and Thwin SS et al (2004) The relationship among physicians' specialty, perceptions of the risks and benefits of adjuvant tamoxifen therapy, and its recommendation in older patients with breast cancer Med Care 42(7) 700-706 DOI: 10.1097/01.mlr.0000129905.64831.5d PMID: $\underline{15213495}$

20. Taylor $\mathrm{R}$ and Taguchi $\mathrm{K}$ (2005) Tamoxifen for breast cancer chemoprevention: low uptake by high-risk women after evaluation of a breast lump Ann Fam Med 3(3) 242-247 DOI: 10.1370/afm.284 PMID: 15928228 PMCID: 1466885

21. Kinney AY, Richards $C$ and Vernon SW et al (1998) The effect of physician recommendation on enrollment in the breast cancer chemoprevention trial Prev Med 27(5 Pt 1) 713-719 DOI: 10.1006/pmed.1998.0349 PMID: 9808803

22. Rondanina G, Puntoni M and Severi G et al (2008) Psychological and clinical factors implicated in decision making about a trial of low-dose tamoxifen in hormone replacement therapy users J Clin Oncol 26(9) 1537-1543 DOI: 10.1200/JC0.2007.13.6739 PMID: 18349406

23. Cuzick J, Sestak I and Thorat MA (2015) Impact of preventive therapy on the risk of breast cancer among women with benign breast disease Breast DOI: 10.1016/j.breast.2015.07.013 PMID: 26255741

24. Blaha P, Dubsky P and Fitzal F et al (2009) Breast cancer chemoprevention - a vision not yet realized Eur J Cancer Care (Engl) 18(5) 438-446 DOI: 10.1111/j.1365-2354.2008.00951.x

25. Reeder JG and Vogel VG (2007) Breast cancer risk management Clin Breast Cancer 7(11) 833-840 DOI: 10.3816/CBC.2007.n.047

26. Vogel VG (2007) Chemoprevention strategies 2006 Curr Treat Options Oncol 8(1) 74-88 DOI: 10.1007/s11864-007-0019-z PMID: $\underline{17634835}$

27. Ravdin PM (2010) The lack, need, and opportunities for decision-making and informational tools to educate primary-care physicians and women about breast cancer chemoprevention Cancer Prev Res 3(6) 686-688 DOI: 10.1158/1940-6207.CAPR10-0100 
28. Narod SA (2015) Tamoxifen chemoprevention-end of the road? JAMA Oncol DOI: 10.1001/jamaoncol.2015.2247

29. Cameron DA (2014) Breast cancer chemoprevention: little progress in practice? Lancet 383(9922) 1018-1020 DOI: $10.1016 /$ $\underline{\text { S0140-6736(13)62555-6 }}$

30. Port ER, Montgomery LL and Heerdt AS et al (2001) Patient reluctance toward tamoxifen use for breast cancer primary prevention Ann Surg Oncol 8(7) 580-585 DOI: 10.1007/s10434-001-0580-9 PMID: 11508619

31. Fagerlin A, Zikmund-Fisher BJ and Nair $\vee$ et al (2010) Women's decisions regarding tamoxifen for breast cancer prevention: responses to a tailored decision aid Breast Cancer Res Treat 119(3) 613-620 DOI: 10.1007/s10549-009-0618-4

32. Kaplan CP, Kim SE and Wong ST et al (2012) Willingness to use tamoxifen to prevent breast cancer among diverse women Breast Cancer Res Treat 133(1) 357-366 DOI: 10.1007/s10549-012-1960-5 PMID: 22315131 PMCID: 4039196

33. Heisey R, Pimlott $\mathrm{N}$ and Clemons $\mathrm{M}$ et al (2006) Women's views on chemoprevention of breast cancer: qualitative study Can Fam Physician 52 624-625 PMCID: 1531726

34. Paterniti DA, Melnikow J and Nuovo J et al (2005) "I'm going to die of something anyway": women's perceptions of tamoxifen for breast cancer risk reduction Ethn Dis 15(3) 365-372 PMID: 16108294

35. Waters EA, Weinstein ND and Colditz GA et al (2009) Explanations for side effect aversion in preventive medical treatment decisions Health Psychol 28(2) 201-209 DOI: 10.1037/a0013608 PMID: 19290712 PMCID: 2657933

36. Bober SL, Hoke LA and Duda RB et al (2004) Decision-making about tamoxifen in women at high risk for breast cancer: clinical and psychological factors J Clin Oncol 22(24) 4951-4957 DOI: 10.1200/JC0.2004.05.192 PMID: 15598980

37. Herberman RB, Pearce HL and Lippman SM et al (2006) Cancer chemoprevention and cancer preventive vaccines-a call to action: leaders of diverse stakeholder groups present strategies for overcoming multiple barriers to meet an urgent need Cancer Res 66(24) 11540-11549 DOI: 10.1158/0008-5472.CAN-06-4122 PMID: 17158189

38. Veronesi U, Maisonneuve P and Decensi A (2007) Tamoxifen: an enduring star J Natl Cancer Inst 99(4) 258-260 DOI: 10.1093/jnci/ djk072 PMID: 17312297

39. Tanne JH (2006) Court awards claimant $\$ 13.5 \mathrm{~m}$ in rofecoxib lawsuit

40. Cuzick J, Sestak I and Cawthorn S et al (2015) Tamoxifen for prevention of breast cancer: extended long-term follow-up of the IBIS-I breast cancer prevention trial Lancet Oncol 16(1) 67-75 DOI: 10.1016/S1470-2045(14)71171-4

41. Cuzick J, Wickerham $L$ and Powles $T$ (2015) Letter to editor re: tamoxifen chemoprevention-end of the road? JAMA Oncol (submitted)

42. Cuzick J, Thorat MA and Andriole G et al (2014) Prevention and early detection of prostate cancer Lancet Oncol 15(11) e484-e492 DOI: 10.1016/S1470-2045(14)70211-6 PMID: 25281467 PMCID: $\underline{4203149}$

43. Thompson IM, Goodman PJ and Tangen CM et al (2003) The influence of finasteride on the development of prostate cancer N Engl J Med 349(3) 215-224 DOI: 10.1056/NEJMoa030660 PMID: 12824459

44. Andriole GL, Bostwick DG and Brawley OW et al (2010) Effect of dutasteride on the risk of prostate cancer N Engl J Med 362(13) 1192-1202 DOI: 10.1056/NEJMoa0908127 PMID: 20357281

45. Robinson D, Garmo H and Bill-Axelson A et al (2013) Use of 5alpha-reductase inhibitors for lower urinary tract symptoms and risk of prostate cancer in Swedish men: nationwide, population based case-control study BMJ $346 \mathrm{f3406}$ DOI: 10.1136/bmj. $\underline{\mathrm{f} 3406}$

46. Thompson IM, Jr., Goodman PJ and Tangen CM et al (2013) Long-term survival of participants in the prostate cancer prevention trial N Engl J Med 369(7) 603-610 DOI: 10.1056/NEJMoa1215932 PMID: 23944298 PMCID: $\underline{4141537}$ 
47. Schmitz-Drager BJ, Schoffski $O$ and Marberger $M$ et al (2014) Risk adapted chemoprevention for prostate cancer: an option? Recent results Cancer Res 202 79-91 DOI: 10.1007/978-3-642-45195-9_10

48. Cuzick J, Thorat MA and Bosetti C et al (2015) Ann Oncol 26(1) 47-57 DOI: 10.1093/annonc/mdu225 PMCID: 4269341

49. Grimshaw E (2014) Aspirin Sales Go Through the City's Roof Western Daily Press (Bristol, UK) (http://www.westerndailypress. co.uk/Aspirin-sales-city-s-roof/story-22709471-detail/story.html)

50. Off-patent Drugs Bill 2014-15, (2014) The House of Commons, United Kingdom

51. DeCensi A, (ed) (2011) Discussion on: exemestane for primary prevention of breast cancer in postmenopausal women: NCIC CTG MAP.3 - a randomized placebo-controlled clinical trial ASCO Annual Meeting

52. Cuzick J, Warwick J and Pinney E et al (2011) Tamoxifen-induced reduction in mammographic density and breast cancer risk reduction: a nested case-control study J Natl Cancer Inst 103(9) 744-752 DOI: 10.1093/jnci/djr079 PMID: 21483019

53. Thorat MA and Cuzick J (2013) Role of aspirin in cancer prevention Curr Oncol Rep 15(6) 533-540 DOI: 10.1007/s11912-0130351-3 PMID: $\underline{24114189}$

54. Thorat MA and Cuzick $J(2015)$ Prophylactic use of aspirin: systematic review of harms and approaches to mitigation in the general population Eur J Epidemiol 30(1) 5-18 DOI: 10.1007/s10654-014-9971-7

55. Mabert K, Cojoc M and Peitzsch C et al (2014) Cancer biomarker discovery: current status and future perspectives Int J Radiat Biol 90(8) 659-677 DOI: 10.3109/09553002.2014.892229 PMID: 24524284

56. Puhan MA, Yu T and Stegeman I et al (2015) Benefit-harm analysis and charts for individualized and preference-sensitive prevention: example of low dose aspirin for primary prevention of cardiovascular disease and cancer BMC Med 13250 DOI: 10.1186/s12916-015-0493-2 PMID: 26423305 PMCID: 4589917

57. Wald NJ and Law MR (2003) A strategy to reduce cardiovascular disease by more than $\mathbf{8 0 \%}$ BMJ 326(7404) 1419 DOI: $10.1136 /$ bmj.326.7404.1419 PMID: 12829553 PMCID: 162259

58. Early breast cancer trialists' collaborative group (1998) Tamoxifen for early breast cancer: an overview of the randomised trials Lancet 351(9114) 1451-1467 DOI: 10.1016/S0140-6736(97)11423-4 PMID: $\underline{9605801}$

59. Decensi A, Bonanni B and Guerrieri-Gonzaga A et al (1998) Biologic activity of tamoxifen at low doses in healthy women $\mathrm{J}$ Natl Cancer Inst 90(19) 1461-1467 DOI: 10.1093/jnci/90.19.1461 PMID: 9776411

60. Decensi A, Robertson C and Viale $G$ et al (2003) A randomized trial of low-dose tamoxifen on breast cancer proliferation and blood estrogenic biomarkers J Natl Cancer Inst 95(11) 779-790 DOI: 10.1093/inci/95.11.779 PMID: 12783932

61. DeCensi A, Bonanni B and Maisonneuve $\mathrm{P}$ et al (2013) A phase-III prevention trial of low-dose tamoxifen in postmenopausal hormone replacement therapy users: the HOT study Ann Oncol 24(11) 2753-2760 DOI: $10.1093 / a n n o n c / m d t 244$ PMID: 23864098

62. Guerrieri-Gonzaga A, Lazzeroni $M$ and Botteri $E$ et al (2013) Effect of low-dose tamoxifen after surgical excision of ductal intraepithelial neoplasia: results of a large retrospective monoinstitutional cohort study Ann Oncol 24(7) 1859-1866 DOI: 10.1093/ annonc/mdt113 PMID: $\underline{23532115}$

63. Trial of low dose tamoxifen in women with breast intraepithelial neoplasia (TAM-01) [database on the Internet] U.S. national institutes of health (2011) [cited 16/09/2015]. Available from: http://clinicaltrials.gov/ct2/show/NCT01357772

64. Low-dose tamoxifen citrate in reducing breast cancer risk in radiation-induced cancer survivors (LDTam) [database on the Internet] U.S. national institutes of health (2010) [cited 16/09/2015]. Available from: http://clinicaltrials.gov/ct2/show/NCT01196936

65. Decensi A, Dunn BK and Puntoni M et al (2012) Exemestane for breast cancer prevention: a critical shift? Cancer Discov 2(1) 25-40 DOI: $\underline{10.1158 / 2159-8290 . C D-11-0248}$ PMID: 22585166 PMCID: $\underline{3354700}$

66. Evans TR, Di Salle E and Ornati G et al (1992) Phase I and endocrine study of exemestane (FCE 24304), a new aromatase inhibitor, in postmenopausal women Cancer Res 52(21) 5933-5939 PMID: 1394219 
67. Johannessen DC, Engan T and Di Salle E et al (1997) Endocrine and clinical effects of exemestane (PNU 155971), a novel steroidal aromatase inhibitor, in postmenopausal breast cancer patients: a phase I study Clin Cancer Res 3(7) 1101-1108 PMID: $\underline{9815789}$

68. Lazzeroni M and DeCensi A Alternate dosing schedules for cancer chemopreventive agents Sem Oncol DOI: $10.1053 / \mathrm{j}$. seminoncol.2015.09.014

69. Lung cancer prevention (PDQ(R)): health professional version (2002) PDQ Cancer information summaries Bethesda (MD)

70. Omenn GS, Goodman GE and Thornquist MD et al (1996) Effects of a combination of beta carotene and vitamin A on lung cancer and cardiovascular disease N Engl J Med 334(18) 1150-1155 DOI: 10.1056/NEJM199605023341802 PMID: 8602180

71. Hennekens $\mathrm{CH}$, Buring JE and Manson JE et al (1996) Lack of effect of long-term supplementation with beta carotene on the incidence of malignant neoplasms and cardiovascular disease N Engl J Med 334(18) 1145-1149 DOI: 10.1056/NEJM199605023 341801 PMID: 8602179

72. The alpha-tocopherol, beta carotene cancer prevention study group (1994) The effect of vitamin $\mathrm{E}$ and beta carotene on the incidence of lung cancer and other cancers in male smokers N Engl J Med 330(15) 1029-1035 DOI: 10.1056/NEJM199404143301501 PMID: $\underline{8127329}$

73. Lee IM, Cook NR and Manson JE et al (1999) Beta-carotene supplementation and incidence of cancer and cardiovascular disease: the women's health study J Natl Cancer Inst 91(24) 2102-2106 DOI: 10.1093/jnci/91.24.2102 PMID: 10601381

74. Lee IM, Cook NR and Gaziano JM et al (2005) Vitamin E in the primary prevention of cardiovascular disease and cancer: the women's health study: a randomized controlled trial JAMA 294(1) 56-65 DOI: 10.1001/jama.294.1.56 PMID: 15998891

75. Lonn E, Bosch J and Yusuf S et al (2005) Effects of long-term vitamin E supplementation on cardiovascular events and cancer: a randomized controlled trial JAMA 293(11) 1338-1347 DOI: 10.1001/jama.293.11.1338 PMID: 15769967

76. Heart protection study collaborative G (2002) MRC/BHF Heart Protection Study of antioxidant vitamin supplementation in 20,536 high-risk individuals: a randomised placebo-controlled trial Lancet 360(9326) 23-33 DOI: 10.1016/S0140-6736(02)09328-5 PMID: 12114037 